\title{
Smoking and acute coronary heart disease: a comparative study
}

\author{
KILLIAN ROBINSON, * RONÁN M CONROY, RISTEARD MULCAHY \\ From the Cardiac Department and Department of Preventive Cardiology, St Vincent's Hospital and \\ University College, Dublin, Ireland
}

SUMMARY Nine hundred and seventy eight patients with a first documented myocardial infarction were studied to detect smoking related differences in clinical profile and in-hospital outcome. The distribution of infarct sites differed significantly between smokers and non-smokers. Smokers had higher peak cardiac enzyme concentrations. In spite of this, smokers had a better prognosis than non-smokers.

There are important differences between smokers and non-smokers, both in clinical profile and in-hospital outcome, which may reflect a difference in the nature of the underlying coronary disease.

Smoking is a major risk factor for coronary heart disease. Although the long term prognosis after a first myocardial infarction has been compared in smokers, non-smokers, and ex-smokers, ${ }^{1}$ the relation of smoking status to the manifestations of acute coronary heart disease remains unclear.

The purpose of this study was to examine the extent to which smokers, non-smokers, and exsmokers show discernible differences in clinical profile and in-hospital outcome after a first myocardial infarction.

\section{Patients and methods}

From January 1980 to April 1985 inclusive, all patients admitted to the coronary care unit of St Vincent's Hospital with a first episode of unstable angina or myocardial infarction were included in a computerised register.

Myocardial infarction was diagnosed when there was typical cardiac pain at rest with abnormal $Q$ waves in the electrocardiogram or a twofold or greater rise in serial cardiac enzymes (serum glutamic oxaloacetic acid transaminase, creatine kinase, and lactate dehydrogenase) or both. Unstable angina was diagnosed on the basis of cardiac pain at rest with serial ST and T wave changes in the electrocardio-

Requests for reprints to Mr Ronán M Conroy, Cardiac Department, St Vincent's Hospital, Elm Park, Dublin 4, Ireland.

*Present address: Cardiac Department, St Bartholomew's Hospital, West Smithfield, London EC1A 7BE.

Accepted for publication 18 August 1988 gram but with normal or a less than twofold increase in the activity of cardiac enzymes.

The site of infarction was classified as anteroseptal, when the electrocardiographic changes were in leads V1-V4; anterolateral with changes in leads V3-V6; and inferior with changes in II, III, and a Vf, with or without changes in V4-V6. Patients with changes in V1-V6 were classified as having combined anteroseptal/anterolateral infarctions. Too few patients had infarction at other sites, a site that could not be determined, and left bundle branch block (which precludes identification of infarct site) for statistical comparisons of such groups to be made. These patients were omitted from analyses of infarct site. Non $Q$ wave infarction was diagnosed when there was cardiac pain, a greater than twofold increase in the activity of cardiac enzymes, and no fresh $Q$ waves in the electrocardiogram.

The presence of angina of effort before infarction was recorded, as were smoking habits before infarction. Preinfarction angina was classified as chronic if it had been present for at least three months before admission, and recent if it had appeared less than three months but more than one week before admission. Patients were classified as non-smokers if they had never smoked as many as one cigarette per day regularly, ex-smokers if they had smoked less than one cigarette per day for at least three months before admission, and current smokers if they had regularly smoked at least one cigarette per day in the three months before admission. Pipe and cigar smoking were noted. Current and former pipe or cigar smokers were classified as current or ex-smokers in the same way as cigarette smokers. To be classified as an 
Table 1 Admission characteristics (number (\%)) of the study group

\begin{tabular}{|c|c|c|c|c|c|}
\hline & \multicolumn{3}{|l|}{ Smoking status } & \multirow[b]{2}{*}{ Total } & \multirow[b]{2}{*}{$p$} \\
\hline & Never smoked & Ex-smoker & Current smoker. & & \\
\hline $\begin{array}{l}\text { Sex: } \\
\text { Male } \\
\text { Female } \\
\text { Mean age (SD) } \\
\text { Cholesterol (SD): }\end{array}$ & $\begin{array}{c}81(40 \cdot 9) \\
117(59 \cdot 1) \\
65 \cdot 6(10 \cdot 5)\end{array}$ & $\begin{array}{cc}196 & (74 \cdot 2) \\
68 & (25 \cdot 8) \\
62 \cdot 8 & (10 \cdot 6)\end{array}$ & $\begin{array}{cc}362 & (70 \cdot 3) \\
153(29 \cdot 7) \\
57.6(10 \cdot 7)\end{array}$ & $\begin{array}{cc}639 & (65 \cdot 4) \\
338 & (34 \cdot 6) \\
60 \cdot 6 & (11 \cdot 2)\end{array}$ & $\begin{array}{l}<0.001 \\
<0.001\end{array}$ \\
\hline $\begin{array}{l}\text { Total (mg/dl) } \\
\text { HDL fraction (mg/dl) } \\
\text { Hypertension present } \\
\text { Diabetes mellitus } \\
\text { Total }\end{array}$ & $\begin{array}{cc}252 & (59 \cdot 5) \\
44 \cdot 1 & (14 \cdot 4) \\
101 & (51 \cdot 5) \\
17 & (9 \cdot 2) \\
198 & (20 \cdot 3)\end{array}$ & $\begin{array}{cc}236 & (50 \cdot 8) \\
39 \cdot 6 & (14 \cdot 6) \\
93 & (36 \cdot 2) \\
20 & (8 \cdot 1) \\
264 & (27 \cdot 0)\end{array}$ & $\begin{array}{cc}241 & (56 \cdot 5) \\
40 \cdot 1 & (15 \cdot 4) \\
124 & (24 \cdot 7) \\
32 & (6 \cdot 5) \\
515 & (52 \cdot 7)\end{array}$ & $\begin{array}{cc}242 & (55 \cdot 9) \\
40 \cdot 6 & (15 \cdot 0) \\
318 & (33.3) \\
69 & (7.4) \\
977 & (100)\end{array}$ & $\begin{aligned} &= 0.040 \\
&= 0.022 \\
&<0.001 \\
& \text { NS }\end{aligned}$ \\
\hline
\end{tabular}

Missing data: age, 7 cases; cholesterol, 202; HDL, 411; hypertension, 22; diabetes, 49.

Significance levels based on $\chi^{2}$ (categorical) and Kruskal-Wallis one way analysis of variance (metric variables). HDL, high density lipoprotein cholesterol.

ex-smoker they had to have stopped for at least three months.

Concentrations of total serum cholesterol and the high density lipoprotein fraction were assayed in blood samples taken in most cases within 12 hours of onset of acute symptoms.

In-hospital mortality and complications were recorded. Complications were categorised by a standard protocol that included a total of 31 individual complications. In this paper we will report on four groups of complications:

Mechanical complications. - left ventricular failure, cardiogenic shock, hypotension.

Ventricular arrhythmias. - ventricular fibrillation, ventricular tachycardia, asystole.

Supraventricular arrhythmias.

Atrioventricular blocks (first, second, and third degree).

Patients were categorised as hypertensive if $(a)$ the mean of all diastolic blood pressure measurements taken on the fourth day after admission was $\geqslant 90$ $\mathrm{mm} \mathrm{Hg}$; or (b) the patient was known to have been treated for hypertension before admission; or $(c)$ at 0 least two of the following three were present: past history of hypertension, electrocardiographic evi- $\vec{D}$

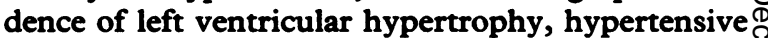
retinopathy.

Peak activities of cardiac enzymes were noted as was the presence of diabetes mellitus.

Categorical variables were analysed by the $\chi^{2}$ test $\vec{c}$ and metric variables by the Wilcoxon rank sum test $\infty$ or Kruskall-Wallis one way analysis of variance by ranks. The latter tests were chosen because some of the metric variables were not normally distributed.

\section{Results}

Nine hundred and seventy seven patients were $\frac{\overline{\bar{B}}}{\vec{z}}$ admitted to the study. A further ten patients who fulfilled the entry criteria and were admitted during the study period were excluded from the study because we could not record their smoking habits.

Table 1 shows the admission characteristics of the group. There were $198(20 \cdot 3 \%)$ patients who had

Table 2 Smoking and manifestations of acute coronary heart disease (number $(\%)$ )

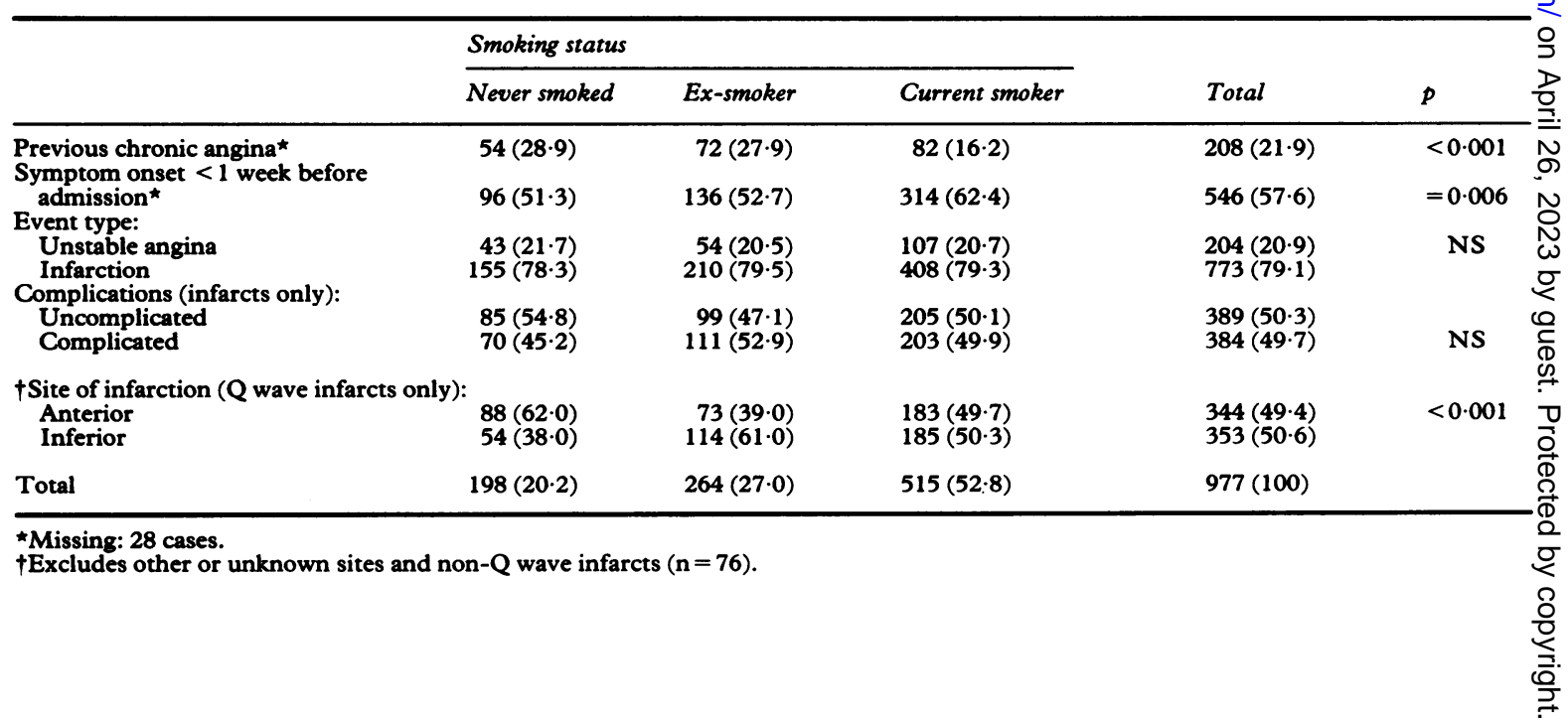


Table 3 Relation of smoking habits to peak increase cardiac enzymes in patients with myocardial infarctions

\begin{tabular}{lclc}
\hline $\begin{array}{l}\text { Smoking } \\
\text { habit }\end{array}$ & $S G O T(I U / l)$ & $C K(I U / l)$ & $L D H(I U / l)$ \\
\hline Never smoked & $206(\mathrm{n}=143)$ & $1146(\mathrm{n}=145)$ & $939(\mathrm{n}=142)$ \\
Ex-smoker & $181(\mathrm{n}=202)$ & $1146(\mathrm{n}=202)$ & $869(\mathrm{n}=200)$ \\
Current smoker & $235(\mathrm{n}=387)$ & $1382(\mathrm{n}=388)$ & $952(\mathrm{n}=386)$ \\
p & 0.241 & 0.010 & $0 \cdot 120$ \\
\hline
\end{tabular}

Significance based on Kruskal-Wallis one way analysis of variance. SGOT, serum glutamic oscaloacetic transaminase; CK, creatine kinase; $\mathrm{LDH}$, lactate dehydrogenase.

never smoked, $515(52 \cdot 7 \%)$ current smokers, and the remaining $264(27.0 \%)$ were ex-smokers. Information on length of time since they had stopped was available on all but 10 ex-smokers; $34.8 \%$ had given up within five years of attack, $37.4 \%$ had given up between five and 15 years, and the remainder more than 15 years before admission. The mean age of smokers was eight years lower than that of patients who had never smoked, and the mean age of exsmokers was three years lower $(p<0.001)$. Concentrations of both total serum cholesterol and high density lipoprotein fraction were higher in patients who had never smoked. Smoking habits differed significantly between the sexes- $34.6 \%$ of women and $12.7 \%$ of men had never smoked. There was also a significantly higher prevalence of hypertension among patients who had never smoked. When multiple logistic regression was used to correct differences in risk factors for differences in age between smokers and non-smokers, both sex and hypertension were still significantly associated with smoking status $(p<$ 0.001 ) while cholesterol and high density lipoprotein fraction were not ( $p=0.263$ and 0.320 respectively).

Current smokers were less likely to have had chronic angina of effort before infarction (table 2) and a higher proportion of them had had symptoms for less than a week before admission, but when multiple logistic regression was used to correct for differences in age distribution, neither chronic angina nor rapid onset of symptom was associated with smoking status
( $p=0.581$ and 0.265 respectively). The proportion of patients whose first overt symptoms of coronary heart disease occurred within a week of admission was similar among non-smokers $(51.3 \%)$ and exsmokers $(52 \cdot 7 \%)$, but higher among current smokers $(62 \cdot 4 \%)$.

Smoking habits were not related to type of episode (unstable angina or infarction) and among patients with infarction they were not related to the occurrence of complications. However, among patients with infarctions there was a significant association between site of infarction and smoking habits; anterior infarction was more common in patients who had never smoked.

Among patients with myocardial infarction there was no relation between smoking habits and peak activities of serum glutamic oxaloacetic acid transaminase or lactic dehydrogenase. The peak concentration of creatine kinase was higher in current smokers (table 3).

Table 4 records the in-hospital complications and outcome in relation to smoking. Many patients had more than one complication. Patients who had never smoked had a higher risk of death and mechanical complications, notably cardiogenic shock. Rare complications in which there was no difference between smoking groups are omitted from the table. Two infrequent complications were associated with smoking status. Junctional rhythm, which occurred in 12 $(1 \cdot 2 \%)$ cases, was more common among patients who had never smoked $(3.5 \%)$ than among current or former smokers $(0.6 \%)(p=0.003)$ and mitral incompetence was also more common in patients who had never smoked, with only one of the four cases occurring in current or ex-smokers ( $p=0.032$ ). Because smoking status and site of infarction were strongly associated we performed a logistic regression analysis to examine the effect of smoking on inhospital end points independently of other factors.

Table 5 shows the relation of smoking habits to death, left ventricular failure, and mechanical complications, corrected for age and the presence of

Table 4 Relation of smoking to in-hospital mortality and complications (number (\%))

\begin{tabular}{|c|c|c|c|c|c|c|}
\hline \multirow[b]{3}{*}{$\begin{array}{l}\text { Died in hospital } \\
\text { Cardiogenic shock } \\
\text { LV failure } \\
\text { Hypotension } \\
\text { Ventricular fibrillation } \\
\text { Any mechanical complication } \\
\text { Any ventricular arrhythmia } \\
\text { Supraventricular complications } \\
\text { Atrioventricular block }\end{array}$} & & \multicolumn{3}{|l|}{ Smoking habit } & \multirow[b]{2}{*}{ Total } & \multirow[b]{2}{*}{$p$} \\
\hline & & Never smoked & $E x$-smoker & Current smoker & & \\
\hline & - & $\begin{array}{l}33(16 \cdot 7) \\
19(9 \cdot 6) \\
43(21 \cdot 7) \\
12(6 \cdot 1) \\
10(5 \cdot 1) \\
64(32 \cdot 3) \\
16(8 \cdot 1) \\
17(8 \cdot 6) \\
16(8 \cdot 1)\end{array}$ & $\begin{array}{r}19(7 \cdot 2) \\
8(3 \cdot 0) \\
44(16 \cdot 7) \\
7(2 \cdot 7) \\
19(7 \cdot 2) \\
57(21 \cdot 6) \\
26(9 \cdot 8) \\
27(10 \cdot 2) \\
14(5 \cdot 3)\end{array}$ & $\begin{array}{l}28(5 \cdot 4) \\
20(3 \cdot 9) \\
89(17 \cdot 3) \\
24(4 \cdot 7) \\
35(6 \cdot 8) \\
111(21 \cdot 6) \\
54(10 \cdot 5) \\
47(9 \cdot 1) \\
32(3 \cdot 2)\end{array}$ & $\begin{array}{rr}80 & (8 \cdot 2) \\
47 & (4 \cdot 8) \\
176 & (18 \cdot 0) \\
43 & (4 \cdot 4) \\
64 & (6 \cdot 6) \\
232 & (23 \cdot 7) \\
96 & (9 \cdot 8) \\
91 & (9 \cdot 1) \\
62 & (6 \cdot 2)\end{array}$ & $\begin{aligned}<0.001 \\
=0.002 \\
\text { NS } \\
\text { NS } \\
\text { NS } \\
=0.006 \\
\text { NS } \\
\text { NS } \\
\text { NS }\end{aligned}$ \\
\hline
\end{tabular}

See text for definition complications. Information on complications was missing in one case. LV, left ventricular. 
Table 5 Effects of smoking, age, and type of acute episode on inpatient outcome, assessed by logistic regression

\begin{tabular}{lccc}
\hline & \multicolumn{2}{l}{ Outcome } & \\
\cline { 2 - 4 } & $\begin{array}{l}\text { Died in } \\
\text { hospital }\end{array}$ & $\begin{array}{l}\text { Cardiogenic } \\
\text { shock }\end{array}$ & $\begin{array}{l}\text { Any } \\
\text { mechanical } \\
\text { complication }\end{array}$ \\
\hline Effect of: & 1.04 & 1.71 & 1.35 \\
\hline Current smoker: & 0.896 & 0.221 & 0.140 \\
$\begin{array}{c}\text { Relative risk } \\
\text { p }\end{array}$ & 1.92 & 2.48 & 1.25 \\
$\begin{array}{l}\text { Never smoked: } \\
\text { Relative risk }\end{array}$ & 0.043 & 0.042 & 0.332 \\
$\begin{array}{c}\text { p } \\
\text { Age: }\end{array}$ & 1.09 & 1.08 & 1.06 \\
Relative risk & $<0.001$ & $<0.001$ & $<0.001$ \\
$\begin{array}{c}\text { p } \\
\text { Rnterior M I: }\end{array}$ & 2.23 & 2.52 & 3.80 \\
Relative risk & 0.001 & 0.003 & $<0.001$ \\
p & & &
\end{tabular}

Anterior infarction $=1$; all other events $=0$.

anterior myocardial infarction. Smoking habits were analysed as two separate variables: whether the patient had ever smoked and whether the patient was a current smoker on admission. The effect of each factor is presented as a relative risk and its associated probability. The relative risk for age although small is highly significant, since it represents the relative risk associated with a unit increase in age. All other relative risks are those associated with the presence of the factor. Patients who had never smoked had a higher mortality and a higher rate of left ventricular failure which were independent of their older age and higher prevalence of anterior myocardial infarction. In contrast, patients who were current smokers at time of admission were not at a significantly higher risk than ex-smokers.

\section{Discussion}

Cigarette smoking is a major risk factor for coronary heart disease and those who stop have a more favourable prognosis after myocardial infarction. ${ }^{1}$ Pipe and cigar smoking are also associated with an increased coronary mortality, ${ }^{2}$ although this effect may be less pronounced than with cigarette smoking. ${ }^{23}$ Smoking may cause myocardial infarction not only by accelerating the development of atherosclerosis ${ }^{45}$ but also by exerting thrombotic ${ }^{6}$ or vasospastic $^{7}$ effects. The arrhythmogenic effect of smoking increases the risk of life threatening arrhythmias and sudden death. Myocardial infarction can occur in smokers with normal or nearly normal coronary arteries; this is a common finding in young, heavy smokers. ${ }^{8}$

Current smokers with a first acute coronary event in this study were younger and more likely to be male. They were less likely to have hypertension and they
Robinson, Conroy, Mulcahy

had lower concentrations of total and high density.lipoprotein cholesterol.

In our patients, infarct size, estimated enzy matically, was larger in current smokers than in nonsmokers, although this effect reached statistical sig $\frac{\bar{\sigma}}{\mathrm{c}}$. nificance only for creatine kinase. In patients with occlusion of the left anterior descending coronarye artery, smoking had an independent adverse effect ons left ventricular function. ${ }^{9}$ This was attributed to $\vec{b}$ possible failure of development of collateral flow insmokers. Such a mechanism would also account forw the larger infarcts seen in our patients.

Despite this, the outcome was better in smokers? than non-smokers. This may be explained by thes difference in distribution of site of infarction in the various groups. Different risk factor profiles may be responsible for different patterns of coronary disease ${ }_{\circ}$ and we noted a significant association between site of infarction and smoking habits, with an excess of anterior infarctions among patients who had nevero smoked. One previous study noted a relation of site巴 of infarction to smoking habits, ${ }^{10}$ but the authors did not distinguish between non-smokers and exsmokers and they reported an excess of inferioro infarctions in current smokers rather than in currenio smokers and ex-smokers. The greater proportion of inferior infarctions in smokers suggests a greater prevalence of left coronary disease in non-smokers and, possibly, a true smoking related effect on the right coronary artery. Furthermore, right coronaryo occlusion may result not only in damage to the lef $\mathcal{L}_{\text {}}$ ventricle but also to the right. Right ventriculare infarction may not, however, have the same adverse prognostic implications as left ventricular infarction and this may explain the apparently contradictory findings of a better prognosis for smokers in the faced of a larger infarct size. ${ }^{11}$

In contrast to the studies cited above, when weo entered smoking habits as two variables-whether. the patient had ever smoked and whether they were ao current smoker-into a logistic regression we were able to distinguish between these two features, at the same time correcting the analysis for age ands presence of anterior infarction, both of which were? related to smoking habits. The analysis showed first that the effect of smoking on prognosis is indepen-o dent of both age and infarction site and secondly that the effect of smoking on prognosis is not the result of a better prognosis in current smokers, but of a worse prognosis in patients who have never smoked. Ex 0 smokers and current smokers had a similar prog nosis, despite the fact that current smokers had the largest and ex-smokers the smallest infarctions, 0 estimated enzymatically.

It is important to bear in mind that the patients? studied had survived long enough to be admitted to 
coronary care. The apparent difference in prognosis between non-smokers and current or ex-smokers may have arisen because a larger proportion of smokers died before admission to hospital. There are no published data to confirm this hypothesis. Similarly, the adverse in-hospital prognosis associated with anterior infarction ${ }^{10}$ may be the explanation for the higher death rate in non-smokers.

There are important differences between smokers and non-smokers in the manifestations of acute coronary heart disease. Apart from the difference in aetiology, smokers and non-smokers show differences not only in size and site of infarction, but also in in-hospital prognosis.

We thank the Medical Records Department of St Vincent's Hospital for their valuable help in this study and the Computer Centre of University College, Dublin.

\section{References}

1 Mulcahy R. Influence of cigarette smoking on morbidity and mortality after myocardial infarction. $\mathrm{Br}$ Heart J 1983;49:410-5.

2 Hickey N, Mulcahy R, Daly L, Graham I, O'Donoghue $S$, Kennedy C. Cigar and pipe smoking related to four year survival of coronary patients. Br Heart J 1983; 49:423-6.

3 US Department of Health, Education and Welfare.
Smoking and health: a report of the Surgeon General. 1979 DHEW Publications No (PHS) 79-500066.

4 Ramsdale DR, Faragher EB, Bray CL, Bennett DH, Ward C, Beton DC. Smoking and coronary artery disease assessed by routine coronary angiography. $\mathrm{Br}$ Med J 1985;290:197-200.

5 Libow M, Schlant RC. Smoking and heart disease. Prog Cardiol 1982;11:131-61.

6 Martin JL, Wilson JR, Ferraro N, Laskey WK, Kleaveland JP, Hirshfeld JW. Acute coronary vasoconstrictive effects of smoking in coronary heart disease. Am J Cardiol 1984;54:56-60.

7 McKenna WJ, Chew CYC, Oakley CM. Myocardial infarction with normal coronary angiogram. Possible mechanism of smoking risk in coronary artery disease. Br Heart J 1980;43:493-8.

8 Sugrue DD, Thompson GR, Oakley CM, Trayner IM, Steiner RE. Contrasting patterns of coronary atherosclerosis in normocholesterolaemic smokers and patients with familial hypercholesterolaemia. $\mathrm{Br} \mathrm{Med}$ J 1981;ii:1358-60.

9 McKenzie WB, McCredie RM, McGilchrist CA, Wilcken DEL. Smoking: a major predictor of left ventricular function after occlusion of the left anterior descending coronary artery. $B r$ Heart $J$ 1986;56: 496-500.

10 Thanavaro S, Klieger RE, Province MA, et al. Effect of infarct location on the in-hospital prognosis of patients with a first transmural myocardial infarction. Circulation 1982;66:742-7.

11 Strauss HD, Sobel BE, Roberts R. The influence of occult right ventricular infarction on enzymatically estimated infarct size, hemodynamics and prognosis. Circulation 1980;62:503-8. 